\title{
ANALISA INVESTIGASI STATIC FORENSICS SERANGAN MAN IN THE MIDDLE BERBASIS ARP POISONING
}

\author{
Gede E A Kamajaya ${ }^{1}$, Imam Riadi ${ }^{2}$, Yudi Prayudi ${ }^{3}$ \\ Email: 19ede.aristya@gmail.com,imam.riadi@is.uad.ac.id2,prayudi@uii.ac.id3 \\ Program Studi Magister Teknik Informatika - Universitas Islam Indonesia1, 3 Program Studi Sistem Informasi, \\ Universitas Ahmad Dahlan, Yogyakarta, Indonesia2
}

(Naskah masuk: 10 Maret 2020, diterima untuk diterbitkan: 15 Maret 2020)

\begin{abstract}
Abstrak
Kebutuhan akan akses internet saat ini sangat dibutuhkan oleh hampir semua orang khususnya wi-fi (wireless fidelity). Seiring meningkatnya pengguna pada wi-fi saat ini berbanding lurus dengan kejahatan yang mengeksploitasi wi-fi dengan melancarkan serangan berbahaya dengan tujuan untuk mendapatkan informasi dengan cara ilegal seperti serangan Man In The Middle berbasis ARP Poisoning. Dimana penyerang menggunakan teknik menyadapan pada frame data dalam jaringan lokal, kemudian mengubah lalu lintas data atau memberhentikan lalu lintas data. Penelitian ini dilakukan dengan menerapkan pendekatan metode Statik forensik, untuk mendeteksi aktivitas ilegal yang terjadi di dalam jaringan Wifi. Proses investigasi dibagi menjadi sepuluh tahapan, dimulai dari proses preparation, detection, incident respon,collection, examination,presevations, examinations, analysis, investigation dan reporting. penelitian ini akan difokuskan pada analisa network trafik untuk proses penemuan barang bukti digital berupa informasi, traffik data dari serangan Man In The Middle berbasis ARP Poisoning. Hasil dari penelitian ini dapat menganalisa data dan menemukan barang bukti maupun informasi pelaku yang dapat dipertanggung jawabkan.
\end{abstract}

Kata kunci: Wi-Fi, Man in the middle, Static forensics, ARP poisoning

\section{ARP POISONING BASED ON MAN IN THE MIDDLE ATTACK IN STATIC FORENSIC INVESTIGATION}

\begin{abstract}
The need for internet access is currently needed by almost everyone, especially Wi-Fi (wireless fidelity). As the increase in users on Wi-Fi is now directly proportional to the crime that exploits Wi-Fi by launching malicious attacks with the aim of obtaining information through illegal means such as ARP Poisoning Man In The Middle attacks. Where the attacker uses tapping techniques on data frames in the local network, then changing data traffic or stopping data traffic. This research was conducted by applying the static forensic method approach, to detect illegal activities that occur within the Wifi network. The investigation process is divided into ten stages, starting from the process of preparation, detection, incident response, collection, examination, pre-evaluation, examination, analysis, investigation and reporting. This research will focus on traffic network analysis for the discovery of digital evidence in the form of information, data traffic from the ARP Poisoning Man In The Middle attack. The results of this study aim to analyze data and find evidence and information that can be accounted for the perpetrators.
\end{abstract}

Keywords: Wi-Fi, Man in the middle, Static forensics, ARP poisoning

\section{PENDAHULUAN}

Indonesia merupakan salah satu negara yang memiliki tingkat penggunaan internet yang cukup tinggi [1], penggunanya dari tahun ke tahun meningkat dari angka yang sangat signifikan. Hal ini terbukti dalam infografis riset yang dilakukan Asosiasi Penyedia Jasa Internet Indonesia (APJII) yang dimuat dalam situs web.kominfo.go.id, pengguna internet di Indonesia pada tahun 2018 telah mencapai angka 171,17 juta pengguna dari jumlah populasi penduduk 264,16 juta orang.
Wifi (wireless fidelity) public atau jaringan nirkabel merupakan salah satu sarana yang begitu penting dalam peningkatan jumlah pengguna internet di Indonesia. Wifi juga menawarkan kemudahan dalam mengakses dan kecepatan tinggi serta harga yang terjangkau, sehingga pengguna internet semakin antusias untuk menggunakan wireless walaupun dengan tingkat keamanan yang rendah [2].

Beberapa praktisi IT sebelumnya telah melakukan penelitian terkait penanganan serangan MITM berbasis ARP Poisoning dengan berbagai 
metode. Seperti yang telah dilakukan [4], yang membahas tentang pencegahan serangan ARP poisoning dengan konsep menggunakan openwrt. Kemudian [5]. membahas tentang pencegahan serangan MITM berbasis ARP poisoning dengan cara menyempurnakan ARP. Kedua penelitian tersebut hanya membahas tentang bagaimana cara deteksi dan pencegahan tetapi kurang memperhatikan tahap investigasi forensik. Investigasi forensik merupakan tahapan setelah pencegahan yang bertujuan untuk menemukan dan mengambil informasi sebagai barang bukti kejahatan cybercrime. sehingga dapat diterima di pengadilan. Ini adalah fakta bahwa hanya satu-satunya kemampuan pencegahan forensik komputer adalah sebagai pencegah kejahatan cybercrime [6].

Penelitian ini bertujuan untuk membahas bagaimana melakukan proses tahapan investigasi forensik pada kasus MITM berbasis ARP Poisoning, dengan menerapkan metode static forensics. Ruang lingkup penelitian dilakukan jaringan lokal wifi public di dalam lingkungan Gedung PUSFID. Langkah untuk menganalisis data pembuktian secara forensik oleh investigator (penyidik) [7]. Hasil penelitian ini untuk mengetahui karakteristik dan pola serangan MITM berbasis ARP poisoning dan menemukan informasi pelaku kejahatan cybercrime yang dapat dijadikan barang bukti.

\section{METODE PENELITIAN}

\section{a. Man in the Middle (MITM) Attack}

Serangan Man of the Middle (MITM) adalah metode hacking dimana seorang penyerang meracuni cache ARP dari dua host yang berkomunikasi untuk mencegat komunikasi mereka dengan tujuan menyebabkan eksploitasi host seperti pembajakan sesi, pencurian data sensitif, pencurian dan peniruan identitas login [8]. Serangan ini merupakan salah satu jenis serangan yang berbahaya karena serangan ini dapat terjadi pada berbagai media informasi seperti website, smartphone, dan bahkan surat. Untuk melancarkan serangan MITM, langkah pertama penyerang mengumpulkan alamat MAC korbannya dengan broadcast permintaan ARP ke seluruh jaringan korban. Kemudian, penyerang mengirim balasan ARP ke host korban untuk menghubungkan alamat IP mereka ke alamat MAC-nya. Dengan begitu penyerang dapat intercept / menangkap semua komunikasi diantara browser dan server. Selain itu penyerang memberikan sertifikat palsu baik ke browser maupun server.

Dampak dari serangan ini sangat terasa karena penyerang dapat menyadap, menyisipkan, atau mengubah alur lalu lintas jaringan tanpa terdeteksi. Dengan demikian penyerang dengan mudah dapat melakukan dua sesi yang dienkripsi sekaligus karena penyerang mengetahui rahasia kedua sambungan, sangat mudah untuk mengamati dan manipulasi data yang diberikan diantara server dan browser. Ilustrasi serangan ini seperti yang ditunjukkan pada Gambar 1.

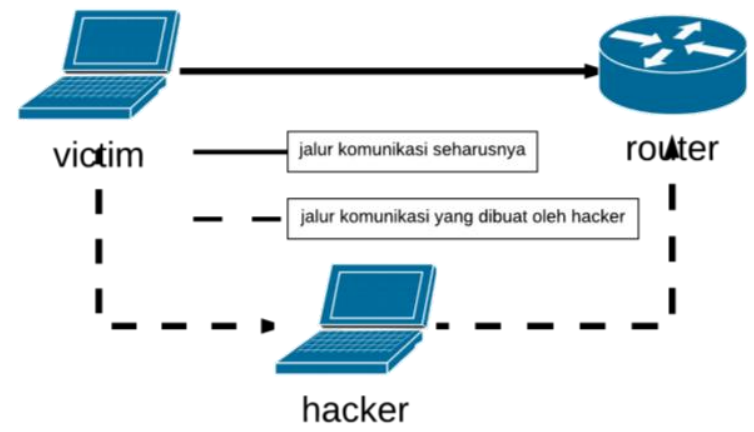

Gambar. 1.Ilustrasi serangan Man In The Middle

\section{b. Static Forensic}

Secara tradisional, static forensics digunakan untuk investigasi insiden digital. Static forensics merupakan pendekatan di mana sistem dianalisis secara forensik setelah mengambil dump memori dan mematikan sistem [7]. Hal tersebut menunjukkan bahwa static forensics fokus pada pemeriksaan salinan duplikat data pada sistem yang akan dianalisis.

Static forensics dilakukan dengan cara menyalin duplikat yang dan mengambil isi memori, seperti file yang dihapus, riwayat penjelajahan web, fragmen file, koneksi jaringan, file yang dibuka, riwayat login pengguna, dll [8]. Data yang dikumpulkan tersebut merupakan representasi dari sistem yang statis dan sifatnya permanen, serta mudah dihilangkan dengan waktu yang singkat.

Pada kasus network forensics, investigator dapat menggunakan teknik static forensics untuk mendapatkan informasi mengenai aktivitas yang terjadi pada jaringan. Static forensics tidak menyediakan skenario lengkap pada saat memeriksa sistem [9] Akan tetapi investigator dapat memasang packet sniffer untuk menangkap trafik yang berjalan pada jaringan dan menganalisisnya. Seperti menggunakan alat batu perangkat lunak FTK (forensics toolkit), Net Intercept, dan Wireshark [6].

\section{c. ARP Poisoning}

Address Resolution Protocol (ARP) merupakan protokol dalam TCP/IP Protocol Suite yang bekerja diantara network layer dan data link layer dan bertanggungjawab dalam melakukan resolusi pencatatan dan pencocokan alamat IP ke dalam alamat Media Access Control (MAC Address) lalu hasilnya letakkan didalam ARP cache [10]. Berdasar pernyataan tersebut dapat dijabarkan protokol ARP melakukan mekanisme pengkorvesian alamat IP ke MAC. Sebagai contoh, ketika client ingin menghubungi router menggunakan IP, client tersebut tidak dapat secara langsung mengirim datanya ke router karena protokol IP bekerja pada network layer, untuk bisa menghubungi router maka client perlu melalui switch yang bekerja pada data link layer untuk meneruskan packet client yang identitasnya menggunakan MAC ke router. Switch tersebut tidak mengerti bahwa IP sebagai identitas client, melainkan switch mengerti bahwa MAC sebagai identitas client. 
Switch perlu mengkonversi protokol IP ke MAC dari setiap client yang terhubung ke router. Mekanisme konversi tersebut diatur sebuah protokol yaitu protokol ARP. Seringkali mekanisme ini dimanfaatkan penyerang untuk melancarkan serangan ARP Poisoning. ARP Poisoning merupakan serangan yang memanfaatkan mekanisme ARP yang dilakukan oleh hacker untuk menyadap dan memodifikasi alur lalu lintas jaringan [11].

Keberadaan ARP poisoning menjadi ancaman serius bagi jaringan komputer saat ini. Karena $A R P$ poisoning dapat memalsukan alamat IP dan MAC yang bisa saja bermaksud untuk mencuri informasi yang bersifat rahasia atau bahkan menimbulkan serangan yang lebih serius yaitu Man In The Middle [11]. Jika serangan ini terjadi, penyerang dapat menyadap, menyisipkan, atau mengubah alur lalu lintas jaringan tanpa terdeteksi. Selain itu, penelitian yang dilakukan [12], ARP poisoning mengacu pada perilaku mendaftarkan pemetaan alamat palsu (IP, MAC) di cache ARP node satu ke node yang lain untuk tujuan jahat. Dengan demikian, ARP Posioning memungkinkan penyerang untuk menguping komunikasi antara node satu dengan yang lain, memodifikasi isi paket, dan membajak koneksi. Gambar 2 menunjukkan ilustrasi serangan ARP Poisoning.

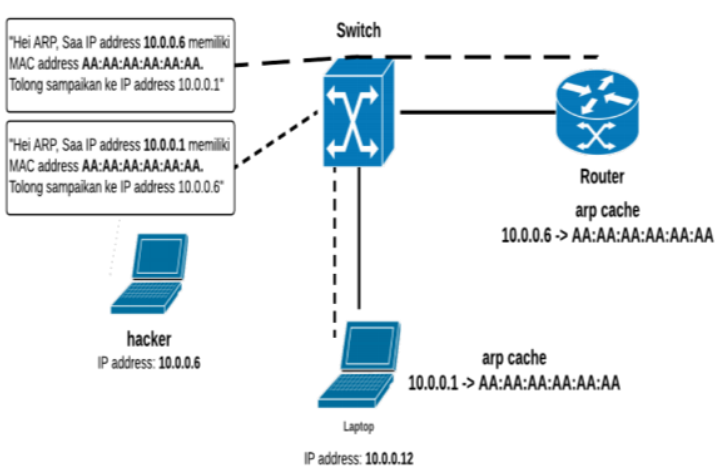

Gambar. 2.Ilustrasi ARP Poisoning

\section{d. Langkah-Langkah Penelitian}

Bab ini menjelaskan bagaimana cara penelitian dilakukan sehingga dapat diketahui rincian tentang urutan langkah-langkah yang dibuat secara sistematis dan dapat dijadikan pedoman yang jelas dalam menyelesaikan permasalahan, membuat analisis terhadap hasil penelitian, serta kesulitan-kesulitan yang dihadapi. Adapun langkah-langkah atau tahapantahapan pada penelitian ini dapat dilihat pada Gambar 3

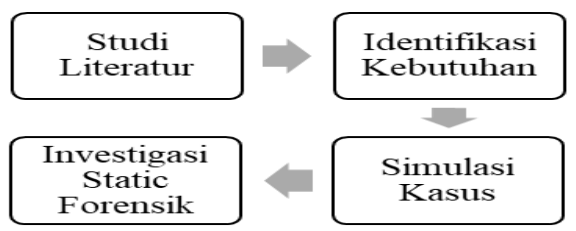

Gambar. 3.Langkah-langkah penelitian

\section{Studi Literatur}

Studi literatur dilakukan untuk mendapatkan informasi mengenai topik penelitian yang dapat bersumber dari dokumen, buku, artikel, atau bahan tertulis lainnya, yang berupa teori, laporan penelitian, atau penemuan sebelumnya, baik sumber yang diperoleh dari online maupun offline.

Kajian pustaka dilakukan terhadap penelitian yang terkait dengan masalah-masalah deteksi MITM berbasis ARP Poisoning, berikut juga metode-metode yang digunakan untuk melakukan proses deteksi dan juga proses investigasi, sehingga dapat menunjang tujuan akhir dilakukannya penelitian ini.

2. Identifikasi Kebutuhan

Identifikasi kebutuhan ini merupakan segala kebutuhan perancangan jaringan wireless yang digunakan sebagai objek penelitian. Penelitian ini tidak merancang jaringan wireless akan tetapi, menggunakan jaringan wifi yang sudah tersedia pada Gedung PUSFID. Kebutuhan jaringan ini digunakan untuk mensimulasikan serangan MITM berbasis ARP Poisoning dan mengivestigasi serangan tersebut untuk menemukan barang bukti.

Persiapan kebutuhan investigasi pada kasus meliputi kebutuhan perangkat keras maupun perangkat lunak. Kebutuhan perangkat keras dalam penelitian ini menggunakan satu buah laptopdengan spesifikasi minimal prosesor intel(r) core i5(tm) cpu @ 2.20ghz dengan RAM 4 GB. Sedangkan kebutuhan perangkat lunak yang dibutuhkan adalah sistem operasi Windows 10, Wireshark, dan Xarp.

3. Simulasi Kasus

Simulasi kasus merupakan tahapan dilakukannya simulasi mengenai pola serangan MITM berbasis ARP Poisoning yang akan dilakukan pada jaringan wifi public Gedung PUSFID. Simulasi ini bertujuan untuk melakukan pengujian keamanan jaringan wifi dengan keberadaan MITM berbasis ARP Poisoning, melakukan tahapan investigasi forensik, menganalisa serangan, dan menyusun kerangka kerjanya.

Simulasi kasus yang akan dijalankan menunjukkan bagaimana pola dari penyerangan MITM berbasis ARP Poisoning. mengumpulkan alamat MAC korbannya dengan broadcast permintaan ARP ke seluruh jaringan korban. Kemudian, penyerang mengirim balasan ARP ke host korban untuk menghubungkan alamat IP mereka ke alamat MAC-nya. Setelah korban terhubung, pelaku dapat dengan mudah melakukan aktivitas sniffing untuk mencari informasi penting milik korban. Kemudian, investigator yang sengaja masuk ke dalam jaringan korban dan berusaha melakukan aktivitas sniffing diantara komunikasi pelaku dan korban lainnya. Gambar 4 menunjukkan gambaran umum dari skenario kasus MITM berbasis ARP Poisoning pada jaringan wifi PUSFID. 


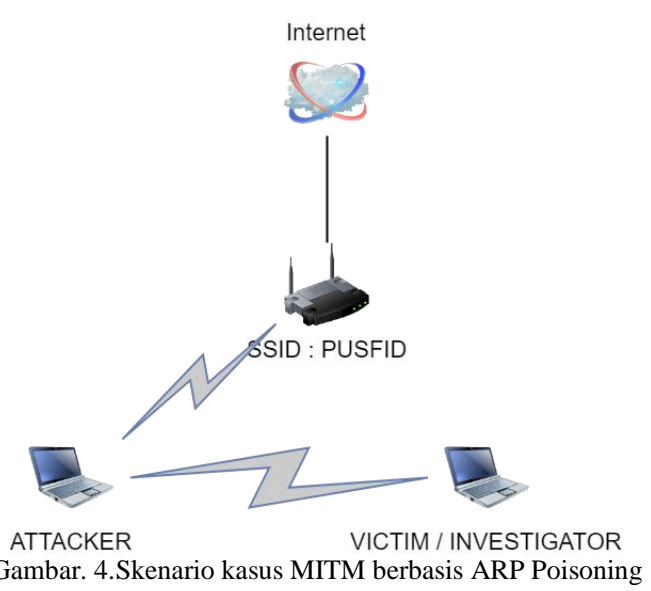

\section{HASIL DAN PEMBAHASAN}

\section{Investigasi Static Forensic}

Pada tahap ini adalah proses dimana investigator mempersiapkan kebutuhannya untuk menginvestigasi serangan ARP Poisoning yang telah dipersiapkan pada simulasi. Tahapan ini akan membahas mulai dari persiapan awal berupa persiapan, deteksi, merespon insiden, pengumpulan informasi, preservasi, dan pemeriksaan.

\section{Persiapan}

Pada tahap ini adalah menyiapkan segala kebutuhan yang diperlukan sebelumnya. Kebutuhan tersebut meliputi perangkat keras dan perangkat lunak yang telah ditentukan sebelumnya.

\section{Deteksi}

Pada dasarnya serangan MITM akan selalu memanfatkan broadcast Arp untuk mencoba melakukan poisioning, dan ketika pelaku memulai serangannya, maka dengan automatis xarp akan memberikan notifikasi adanya serangan Arp seperti yang terlihat pada Gambar 6, dimana terlihat source IP 192.160.1.1 melakukan recquest pada IP 192.160.1.115.

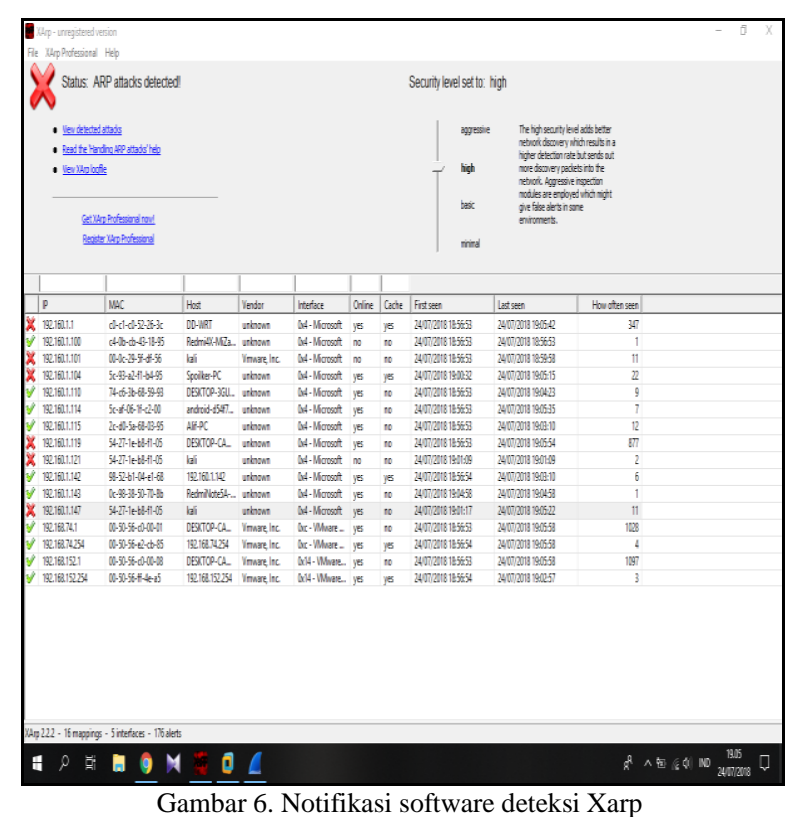

\section{Merespon Insiden}

Berdasarkan proses deteksi yang sudah dilakukan. Insiden respon yang dilakukan adalah investigator masuk ke dalam jaringan serangan MITM berbasis ARP Poisoning dengan menggunakan pendekatan dari sisi user. Pada Gambar 7 menunjukkan bahwa investigator telah masuk ke dalam jaringan serangan MITM berbasis ARP Poisoning dengan ditandai IP. 192.168.1.119. Respon insiden terkait serangan ini dilanjutkan kepada tahap pengumpulan informasi.

\section{Pengumpulan informasi}

Melakukan aktivitas sniffing/menyadap dan melakukan capture / perekaman terhadap paket data lalu lintas jaringan wifi yang sudah terdeteksi ARP poisoning dengan menggunakan aplikasi wireshark.

Perekaman lalu lintas paket data dengan menggunakan wireshark di dalam jaringan ARP poisoning tersebut, dilakukukan selama rentan waktu tertentu untuk menemukan beberapa informasi yang dapat digunakan untuk proses analisa selanjutnya, berikut detil file pcap yang akan dianalisa, seperti yang terlihat pada Gambar 7.

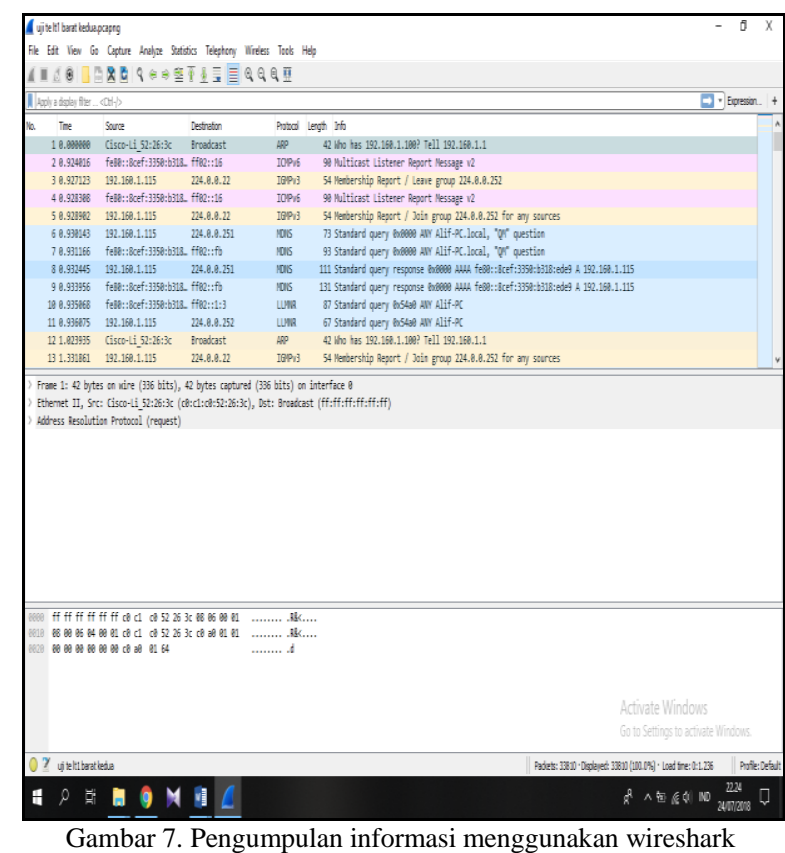

\section{Preservasi}

Tahapan Preservasi, dilakukan dengan menyalin dan mengamankan data maupun informasi yang ditemukan dalam tahap pengumpulan informasi sebelumnya. Kemudian dilakukan dengan mengamankan file hasil perekaman lalu lintas data dalam bentuk ekstrak file berekstensi p.cap menggunakan aplikasi perangkat lunak Wireshark.

\section{Pemeriksaan}

Proses pemeriksaan dilakukan dengan cara memanfaatkan modul hirarki dan comand-comand filterisasi paket dari dari alat bantu perangkat lunak wireshark. Dari hasil pemeriksaan tabel hirarki terdapat 3 objek yang dapat dijadikan sebagai bahan 
analisa yaitu port HTTP, port ARP. Seperti yang terlihat pada Gambar 8.

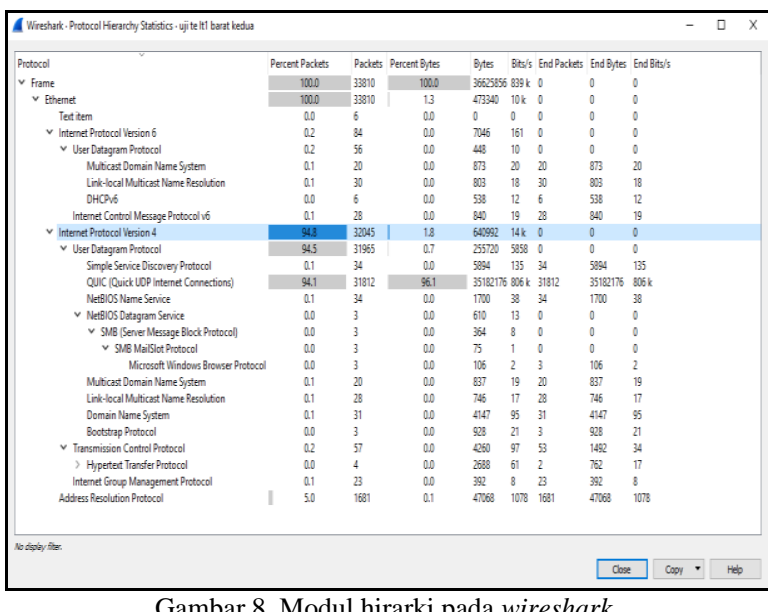

Analisa dan Investigasi

Pada Gambar 9,10, pemeriksaan port ARP pada nomor paket 27900 ditemukan kegiatan ARP broadcast dari MAC address LiteonTe/ source 68:03:95. Isi pesan broadcast request ARP dengan pengirim IP 192.160.1.115 mencoba menghubungi kepada 192.160.1.147 seperti yang ditunjukkan pada Gambar 11. Kemudian pemeriksaan port ARP pada nomor paket 27902 ditemukan kegiatan broadcast reply ARP dari source Azurewav_b8:f1:05 dengan pengirim IP 192.168.1.147 mencoba menghubungi kepada destination LiteonTe_68:03:95 seperti yang ditunjukkan pada Gambar 12. Broadcast reply tersebut terdeteksi duplikasi IP 192.160.1.147 yang digunakan MAC address 54:27:1e:b8:f1:05 dan juga digunakan MAC address 84:16:f9:17:a5:58 seperti yang ditunjukkan pada Gambar 11 dan 12.
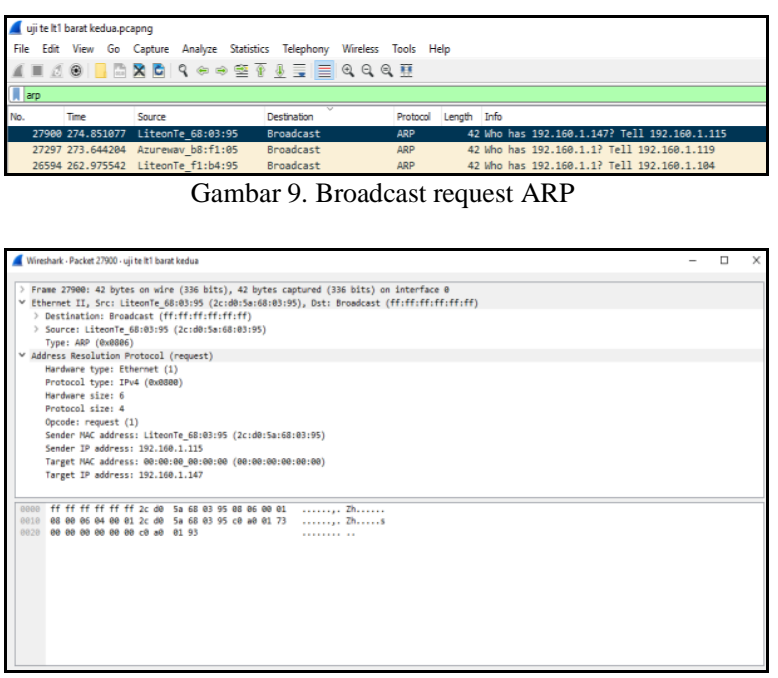

Gambar 10. Isi broadcast request ARP

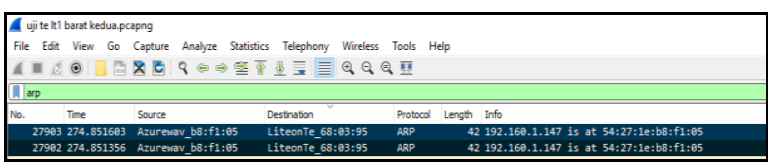

Gambar 11. Broadcast reply ARP

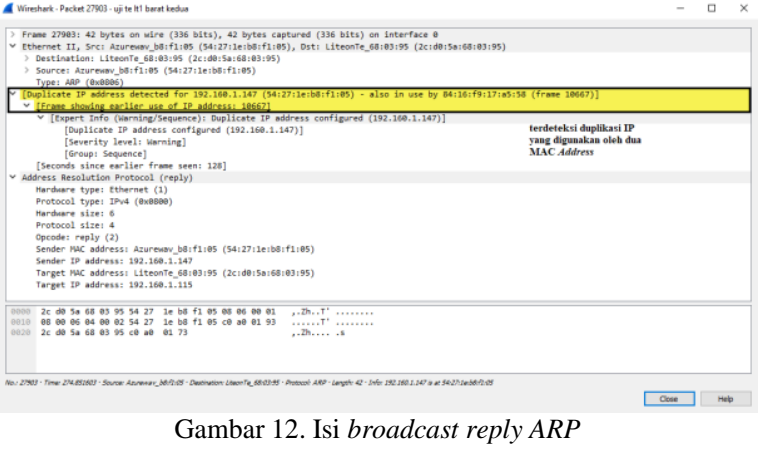

Pada pemeriksaan filterisasi port HTTP seperti yang ditujukkan pada Gambar 14 pada nomor paket 31005 dan 31001, terlihat IP 192.160.1.115 melakukan kegiatan request kepada IP 192.160.1.147 (penyerang), kemudian IP 192.160.1.115 (korban) diarahkan untuk mengakses login pada situs yang kemungkinan sengaja disiapkan. Pemeriksaan lebih lanjut pada port ini dengan memeriksa isi dari kegiatan login tersebut untuk lebih jelasnya dapat dilihat pada Gambar 13.

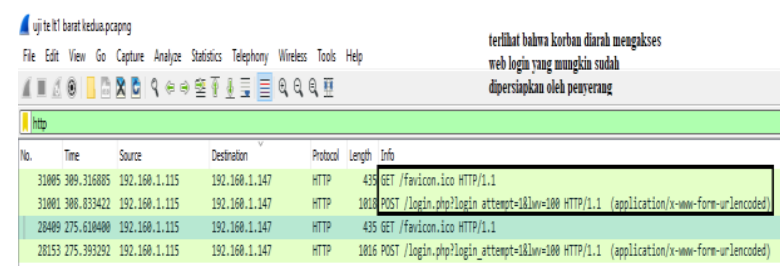

Gambar 13. Pemeriksaan port http

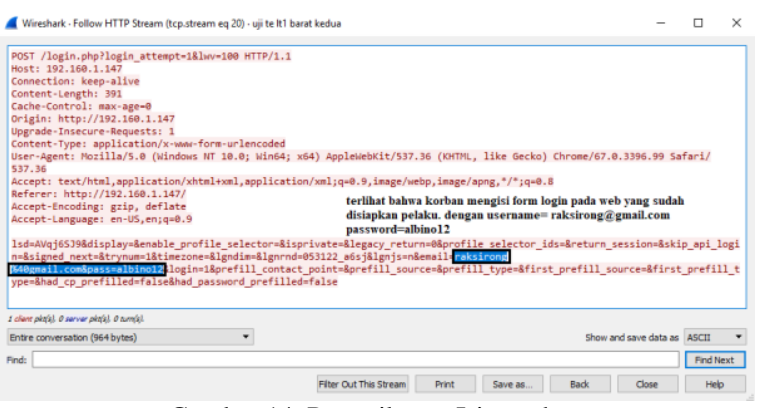

Gambar 14. Pemeriksaan Isi port http

Berdasarkan hasil analisa yang dilakukan dalam kasus MITM berbasis ARP Poisoning ini, dengan menggunakan metode statik forensik dan pendekatan dari sisi user, bedasarkan tahapan -tahapan sebelumnya ditemukan beberapa pentujuk ataupun temuan - temuan yang dapat dijadikan sebagai informasi, yang dapat digunakan sebagai barang bukti, dan dari tahapan-tahapan analisa sebelumnya maka dapat ditarik beberapa kesimpulan sebagai berikut :

- ARP Poisoning, mencoba membuat kembaran atau menyerupai AP yang telah menjadi targetnya, pada kasus ini ditemuklan dua buah MAC Address yang memiliki IP yang sama.

- Mengetahui alamat IP router dan gateway ketika telah berada di dalam jaringan MITM berbasis Arp Poisoning, kemudian deteksi 
serangan Arp poisoning menggunakan Arp detektor.

- Metodologi atau model investigasi yang digunakan untuk menemukan barang bukti pada kasus serangan MITM berbasis ARP Poisoning.

- Analisa port HTTP, dilakukan untuk mengindetifikasi aktifitas yang mencurigakan, dari hasil analisa filterisasi port HTTP, terlihat IP 192.160.1.115 melakukan request ke IP 192.168.1.147 kemudian mengakses login situs dengan host 192.168.1.147 yang kemungkinan sengaja disiapkan. Hasil analisa port http terlihat adanya beberapa file yang mencurigakan, diantaranya file login username=raksirong@gmail.com dan password=albino12, untuk lebih jelasnya dapat dilihat pada Gambar 14.

\section{Presentasi}

Berdasarkan proses atau tahapan investigasi sebelumnya ditemukan beberapa petunjuk ataupun temuan - temuan yang dapat dijadikan sebagai informasi. Temuan ini dapat digunakan sebagai barang bukti. Presentasi barang bukti ini terangkum pada Tabel 1.

Tabel 1. Analisa file Pcap

\begin{tabular}{|c|c|c|c|c|c|c|}
\hline No & Time & Source & Destination & Protocol & Length & Info \\
\hline \multicolumn{7}{|c|}{ Analisa port ARP } \\
\hline 27900 & 274.851077 & $\begin{array}{l}\text { LiteonTe_68:03: } \\
95\end{array}$ & Broadcast & ARP & 42 & $\begin{array}{l}\text { Who has } 192.160 .1 .147 ? \\
\text { Tell 192.160.1.115 }\end{array}$ \\
\hline 27903 & 274.851603 & $\begin{array}{l}\text { Azurewav_b8:f1 } \\
: 05\end{array}$ & $\begin{array}{l}\text { LiteonTe 68:03: } \\
\text { 95 }\end{array}$ & ARP & 42 & $\begin{array}{l}\text { 192.160.1.147 is at } \\
54: 27: 1 \mathrm{le}: 68: \mathrm{fl}: 05\end{array}$ \\
\hline 27902 & | 274.851356 & $\begin{array}{l}\text { Azurewav_b8:t1 } \\
: 05\end{array}$ & $\begin{array}{l}\text { LiteonTe 68:03: } \\
\text { 95 }\end{array}$ & ARP & 42 & $\begin{array}{l}\text { 192.160.1.147 is at } \\
\text { 54:27:1e:188:f1:05 }\end{array}$ \\
\hline \multicolumn{7}{|c|}{ Analisa port HTTP } \\
\hline 31005 & 309.316885 & 192.160.1.115 & 192.160.1.147 & HTTP & 435 & $\begin{array}{l}\text { GET /favicon.ico } \\
\text { HTTP/1.1 }\end{array}$ \\
\hline 31001 & 308.833422 & 192.160.1.115 & 192.160.1.147 & HTTP & 1018 & $\begin{array}{l}\text { POST } \\
\text { /login.plp?plogin_attempt } \\
=1 \& \text { lww }=100 \mathrm{HTTP} / 1.1 \\
\text { (application } / \mathrm{X} \text { - } \mathrm{wWw} \text { - } \\
\text { form-urlencoded) }\end{array}$ \\
\hline
\end{tabular}

Berdasarkan tabel 1, ditemukan duplikasi IP 192.160.1.147 yang digunakan MAC address 54:27:1e:b8:f1:05 dan juga digunakan MAC address 84:16:f9:17:a5:58 pada paket nomor 27902 seperti yang ditunjuk kan pada Gambar 13. Ditemukan entry login username=raksirong@gmail.com dan password=albino12 dari host: 192.168.1.147 pada paket nomor 31001 seperti yang ditunjukkan pada Gambar 14.

\section{KESIMPULAN}

Berdasarkan hasil yang didapatkan pada proses implementasi hasil dan pembahasan, dapat ditarik beberapa kesimpulan yaitu:

- Mendeteksi dan menemukan karakteristik serangan MITM berbasis ARP Poisoning dapat diketahui dengan cara menganalisa broadcast operasi request dan reply pada mekanisme data ARP, dari hasil analisa diketahui terdapat beberapa informasi yang dapat dijadikan perbandingan yaitu IP dan MAC Address.

- Metode pencarian barang bukti dari serangan MITM berbasis ARP Poisoning, dilakukan dengan menggunakan metode sniffing pada jaringan, dengan memanfaatkan modul modul maupun filterisasi pada alat bantu perangkat lunak wireshark dan dari hasil penelitian ditemukan bahwa untuk melakukan proses identifikasi serangan MITM berbasis ARP Poisoning dibutuhkan sebuah metode investigasi forensik yang dapat diimplentasikan dalam jaringan wifi yaitu metode statik forensik. Pendekatan user side cukup efektif dalam proses pengidentifikasi aktifitas serangan MITM berbasis ARP Poisoning. Dengan cara masuk dan sengaja menjadi korban untuk melakukan proses sniffing agar mendapatkan informasi lebih lanjut tentang kemungkina terjadinya aktifitas ilegal yang dilakukan oleh pelaku.

- Penelitian selanjutnya diharapkan dapat mengimplementasikan dari pendekatan baik secara user side maupun dari server side, dikarenakan terbatasnya analisa pencarian barang bukti yang dilakukan pada proses investigasi forensik pada kasus MITM berbasis ARP Poisoning. Implementasi dapat dilakukan pada area publik yang memiliki kemungkinan adanya lebih dari satu macam kejahatan yang memanfaatkan serangan MITM berbasis ARP Poisoning. Selain itu diharapkan dapat mengikuti perkembangan metode serangan yang dilakukan para pengembangan MITM berbasis ARP Poisoning yang berguna untuk pengembangan framework atau model investigasi forensik lebih lanjut dan khusus.

\section{DAFTAR PUSTAKA}

[1] I. Yuliana., 2019. “Adopsi Social Network Analysis (Sna) Dalam Upaya Membangun Ketangguhan Bencana Di Masyarakat," JIKO (Jurnal Inform. dan Komputer), vol. 2, no. 2, pp. 49-54.

[2] O. Nakhila, E. Dondyk, M. F. Amjad, and C. Zou, 2015. "User-side Wi-Fi Evil Twin Attack detection using SSL/TCP protocols," 2015 12th Annu. IEEE Consum. Commun. Netw. Conf. CCNC 2015, pp. 239-244.

[3] H. Shulman and M. Waidner, 2014. "Towards Forensic Analysis of Attacks with DNSSEC," 2014 IEEE Secur. Priv. Work., pp. 69-76.

[4] A. P. Ortega, X. E. Marcos, L. D. Chiang, and C. L. Abad, 2009 "Preventing ARP cache poisoning attacks: A proof of concept using OpenWrt," 2009 Lat. Am. Netw. Oper. Manag. Symp. LANOMS,

[5] S. Y. Nam, D. Kim, and J. Kim, "Enhanced ARP: Preventing, 2010 ARP poisoning-based man-in-the-middle attacks," IEEE Commun. Lett., vol. 14, no. 2, pp. 187-189, 
[6] A. Yasinsac and Y. Manzano, 2001. "Policies to Enhance Computer and Network Forensics," Proc. 2001 IEEE, pp. 5-6,.

[7] M. Rafique and M. N. A. Khan, 2013. "Exploring Static and Live Digital Forensics: Methods, Practices and Tools," Int. J. Sci. Eng. Res., vol. 4, no. 10, pp. 1048-1056,.

[8] G. N. Nayak and S. G. Samaddar, 2010. "Different flavours of Man-In-The-Middle attack, consequences and feasible solutions," Proc. - 3rd IEEE Int. Conf. Comput. Sci. Inf. Technol. ICCSIT 2010, vol. 5, pp. 491-495, 2010.

[9] S. V Khangar, G. H. R. C. E. Nagpur, and R. V Dharaskar, 2012. "Digital Forensic
Investigation for Virtual Machines," vol. 2, no. 6, pp. 663-666,.

[10] D. C. Plummer, 1982. "handbook network forensik,".

[11] Sean Whalen, 2001. "An Introduction to Arp Spoofing," p. 7,.

[12] S. Y. Nam, S. Jurayev, S.-S. Kim, K. Choi, and G. S. Choi, 2012. "Mitigating ARP poisoning-based man-in-the-middle attacks in wired or wireless LAN," EURASIP J. Wirel. Commun. Netw., vol. 2012, no. 1, p. 89,

[13] E. S. Pilli, R. C. Joshi, and R. Niyogi, 2010. "Network forensic frameworks: Survey and research challenges," Digit. Investig., vol. 7, no. 1-2, pp. 14-27, 